\title{
Influences of mood on information processing styles in high and low symptom reporters
}

\section{BACKGROUND}

Negative mood, which has been strongly linked to the presence of medically unexplained symptoms (MUS), is also suggested to modulate the way information is processed (analytic vs. schematic processing style). The present study investigated whether negative mood influences the information processing style differentially in people reporting frequent MUS in daily life.

\section{PARTICIPANTS AND PROCEDURE}

Forty female participants (22 low, 18 high habitual symptom reporters) completed a semantic priming task, as an index of schematic processing, after positive and after negative mood induction in a counterbalanced order. The priming task consisted of neutral or unpleasant body-related and body-unrelated words to assess the specificity of processing style shifts.

\section{RESULTS}

The analyses indicated a non-significant tendency for negative mood to increase priming effects compared to positive mood for the high habitual symptom reporters, while the opposite pattern was found for the low symptom reporters. This differential effect of mood was only seen for neutral body-related words.

\section{CONCLUSIONS}

The current findings suggest that negative mood can trigger schematic processes assumed to be crucial for the emergence of MUS, which may explain the profound link between unpleasantness and elevated symptom reporting in high symptom reporters.

\section{KEY WORDS}

mood influences; schematic processing; semantic priming; habitual symptom reporting

ORganization - Health Psychology, Faculty of Psychology and Educational Sciences, University of Leuven, Leuven, Belgium

AUthors' Contributions - A: Study design - B: Data collection - C: Statistical analysis - D: Data interpretation .

E: Manuscript preparation · F: Literature search · G: Funds collection

Corresponding Author - Prof. Omer Van den Bergh, Health Psychology, Faculty of Psychology and Educational Sciences, Tiensestraat 102, B-3000 Leuven, Belgium, e-mail: omer.vandenbergh@ppw.kuleuven.be

to Cite this ARTICLE - Constantinou, E., Bogaerts, K., Van Diest, I., \& Van den Bergh, O. (2015). Influences of mood on information processing styles in high and low symptom reporters. Health Psychology Report, 3(4), 300-311.

DOI: $10.5114 /$ hpr.2016.55402 


\section{BACKGROUND}

Self-reported physical symptoms not corresponding to organic dysfunction (medically unexplained symptoms - MUS) are quite common in medical care (Kroenke, 2003) and have puzzled researchers exploring the mechanisms underlying this phenomenon.

Cognitive-perceptual approaches to MUS view such symptoms as distortions in the symptom perception process. The main source of such distortions is considered to be the activation of symptom schemata, i.e. representations of prior symptom experiences in memory (Brown, 2004). During symptom perception, afferent information from within the body activates relevant schemata, which are used for the interpretation of the sensory signals (Brown, 2004; Cioffi, 1991). Some people may have chronically activated or sensitized symptom schemata, which require only minimal or even no physiological input to be activated and elicit the subjective experience of a symptom (Brown, 2004). Medically unexplained symptoms phenomena, thus, are considered to result from inappropriate over-activation of symptom schemata.

Support for this notion comes from studies showing that people who tend to experience MUS (e.g. patients with functional syndromes or somatoform disorders) show more cognitive biases towards health-related stimuli (Brown, Kosslyn, Delamater, Fama, \& Barsky, 1999; Lim \& Kim, 2005; Moss-Morris \& Petrie, 2003; Pauli \& Alpers, 2002; Williams, Wasserman, \& Lotto, 2003; Witthöft, Gerlach, \& Bailer, 2006). These findings, although not always consistent in the literature (see Brosschot, 2002 for a summary of inconsistencies), suggest some over-activation of symptom schemata in these groups.

Importantly, these cognitive biases are not a stable feature of high MUS individuals. Rather, situational factors that activate symptom schemata seem to augment cognitive biases to health-related stimuli (Henderson, Hagger, \& Orbell, 2007; Meerman, Verkuil, \& Brosschot, 2011; Skelton \& Strohmetz, 1990), especially for people with a tendency to experience MUS (Bogaerts et al., 2008). One situational factor that may promote such biases is state negative affect. Various studies have repeatedly shown that the presentation of unpleasant cues results in elevated symptom reports (e.g. Bogaerts et al., 2005; de Wied \& Verbaten, 2001; Meagher, Arnau, \& Rhudy, 2001), even in the absence of experimentally induced physical symptoms (Bogaerts, Janssens, De Peuter, Van Diest, \& Van den Bergh, 2010; Constantinou, Bogaerts, Van Diest, \& Van den Bergh, 2013). This effect is more profound for persons experiencing frequent MUS (high habitual symptom reporters; Bogaerts et al., 2010) and cannot be explained by actual physiological arousal changes (Constantinou et al., 2013), which suggests that unpleasant cues act as triggers activating symptom schemata in mem- ory in high habitual symptom reporters (Bogaerts et al., 2010).

This assumed role of negative affect in schematic activations is further supported by research showing that emotion can exert changes in the way people process information (Clore \& Huntsinger, 2007). Specifically, it is proposed that positive and negative moods ${ }^{1}$ serve as information (affect-as-information hypothesis) and as such can lead to different information processing styles. Positive mood as an indication of benign situations promotes the default processing mode, which is typically global, schematic and relational processing, whereas negative mood, as an evolutionary signal of danger or problematic situations, promotes a shift from the default, to more local, item-specific and analytical processing (Schwarz, 2012). This theory has been supported by various studies: when in a positive mood people have a broader attentional scope (Gasper \& Clore, 2002), produce more schema-related false memories during word (Storbeck \& Clore, 2005; Storbeck, 2013) or script recall (Bless et al., 1996) and are more strongly primed during semantic priming tasks (Hänze \& Hesse, 1993; Storbeck \& Clore, 2008). Conversely, negative moods seem to reduce schematic biases, increase bottom-up processing and narrow the scope of attention in such tasks.

These mood-induced processing style shifts seem to be modulated by various factors including individual differences (Gohm \& Clore, 2002). The few studies examining the role of individual differences suggest that this pattern of mood influences may not apply or even be reversed for people with trait characteristics related to negative affect. For example, high trait anxious people were found to provide more biased risk estimations under negative mood (Gasper \& Clore, 1998), while depressed people recalled more false memories for unpleasant rather than pleasant lists (Joormann, Teachman, \& Gotlib, 2009). These findings suggest that for some people negative affect is congruent with their dispositional affect (Gasper \& Clore, 1998) and as such it does not reduce but rather exacerbate affectively congruent schematic influences.

Following these findings and the tenets of the affect-as-information hypothesis, one could assume that also in the context of symptom perception negative affect may lead to a more item-specific/analytical processing style compared to positive affect. However, for individuals experiencing frequent MUS, who presumably have sensitized symptom schemata and also tend to be high in trait negative affect (Van Diest et al., 2005), the opposite pattern may emerge, with negative affect leading to increased reliance on symptom schemata (schematic processing).

\section{PRESENT STUDY}

The present study aimed to directly examine whether induced moods alter the processing style of informa-

\section{Mood} and processing styles in high symptom reporters 
tion differentially in high habitual symptom reporters compared to a low symptom reporting group and whether possible differences in processing style shifts are general or specific to symptom-related information.

A priming task was used to assess processing style shifts (see Storbeck \& Clore, 2008) after positive or negative mood induction. Priming effects, i.e. the reduction in the time needed to respond to a target when preceded by a semantically related prime, are considered to reflect a spreading of activation in memory (Anderson, 1983; Collins \& Loftus, 1975), in the sense that processing the prime activates associated concepts in memory and facilitates the processing of subsequent related stimuli (Neely, 1977).

Because of the dimensional nature of MUS (Hiller, Rief, \& Brähler, 2006), we examined the hypothesized mechanisms using a non-clinical group of high symptom reporters as a proxy to patients experiencing MUS and compared them with low symptom reporters. Hence, participants who were high (HSR) and low habitual symptom reporters (LSR) underwent a semantic classification priming task as an indicator of schematic processing, with prime and target pairs comprised of neutral or unpleasant body-related and body-unrelated words, i.e. man-made objects (body parts/physical symptoms, kitchen utensils/weapons). These different word categories were included in the task to examine whether processing style differences between groups are specific to a symptom schema or more general. Participants completed the task twice after positive and negative mood induction.

We expected that: a) HSR would show more priming effects during negative mood, while LSR would show more priming effects during positive mood, and b) this interaction would be observed mostly for body-related words. Whether it would be seen for neutral body words (body parts), unpleasant body words (bodily symptoms) or both was examined in an exploratory fashion.

\section{PARTICIPANTS AND PROCEDURE}

\section{SAMPLE}

Female students were recruited via advertisements or personal email invitations to participate in a study examining "people's performance in cognitive and emotional tasks". Participants were selected based on their habitual symptom reporting scores assessed with the Checklist for Symptoms in Daily Life (CSD; Wientjes \& Grossman, 1994) and assigned into a high symptom reporting group (HSR) and a low symptom reporting group (LSR) based on the upper and lower quartiles of the CSD (see below).

To reduce the possibility that symptom reports on the CSD were explained by organic factors, we excluded persons reporting a chronic medical condition, or regular medication use. Based on these exclusion criteria, 24 LSR and 19 HSR completed the experiment. Participants were also post hoc excluded if a) they reported extreme values of perceived pleasantness (used as a mood manipulation check) in the opposite direction than expected based on the boxplot function (a score of 4 out of 9 for positive and a score of 9 for negative mood), and b) they were too slow or made too many errors at the priming task. This led to the exclusion of 2 LSR and 1 HSR. Thus, the final sample consisted of $22 \operatorname{LSR}\left(M_{\text {age }}=20.00, S D_{\text {age }}=1.88\right)$ with a mean CSD score of $61.14(S D=9.33)$ and $18 \operatorname{HSR}\left(M_{\text {age }}=19.72, S D_{\text {age }}=2.16\right)$ with a mean CSD score of $109.72(S D=10.77)$. Students received course credit or monetary reward for their participation. The study was approved by the Multidisciplinary Ethical Committee of the Faculty of Psychology and Educational Sciences of KU Leuven.

\section{MATERIALS AND TASKS}

Mood induction stimuli. Positive and negative moods were induced with a combination of emotional pictures and emotionally laden music. Specifically, 20 pleasant and 20 unpleasant pictures ${ }^{2}$ were selected from the IAPS collection (International Affective Picture System; Lang et al., 2005) based on ratings of Belgian students from prior studies, so that the two picture series differed significantly in valence but not in $\operatorname{arousal}^{3}$. During mood induction, each picture was presented on-screen for 6 seconds $(20 \times 6=120 \mathrm{sec}-$ onds of picture viewing). Additionally, a music piece of the same valence as the pictures was presented through headphones to the participants to intensify the emotional experience induced by the pictures (Baumgartner, Esslen, \& Jäncke, 2006). A part of Beethoven's Symphony No. 6, $3^{\text {rd }}$ movement ( 3 min $32 \mathrm{~s}$ ) was presented along with the pleasant pictures to induce a positive mood and a piece from Stravinsky's Rite of Springs, the Sacrificial Dance (3 min $11 \mathrm{~s}$ ) was coupled with the unpleasant pictures to induce a negative mood. As the music pieces were longer than the pictures, the mood induction procedure started with a 1-min period of music-alone presentation, followed by a 2-min period of simultaneous picture-music presentation. Music pieces were selected based on their effectiveness in previous studies (Albersnagel, 1988; Baumgartner et al., 2006), and on the results of a pilot study $(N=12)$, which showed that these music pieces combined with the selected pictures provided satisfactory changes in perceived valence and arousal.

Semantic priming task. Participants performed a semantic classification task consisting of 148 trials (144 experimental, 4 practice trials) twice. During each trial, a fixation cross was presented for $1000 \mathrm{~ms}$ and followed by a prime word (white small letters, 
Arial 22 pt font, on black background) presented for $200 \mathrm{~ms}$. After a $50 \mathrm{~ms}$ inter-stimulus interval, a target word was presented (white capital letters, Arial 22 pt font, on black background) and participants had to categorize the target as a man-made object or a body-related word as soon as possible. The target remained on screen for $2000 \mathrm{~ms}$ or until the participant's response. Trials were separated by an average inter-trial interval of $1000 \mathrm{~ms}$ (varied randomly within a $200 \mathrm{~ms}$ margin).

Words from two categories (man-made objects, body-related words) and two levels of valence (neutral, unpleasant) were used in the task. Four lists with 12 words each were created: kitchen utensils (neutral-object), weapons (unpleasant-object), body parts (neutral-body) and symptoms (unpleasant-body). Six words from each list served as primes and the other six as targets (see Appendix). Pilot data $(N=24)$ indicated similar valence ratings (1 to 9 scale) for the two neutral word lists (kitchen utensils: $M=5.34$, $S D=0.40$; body parts: $M=5.38, S D=0.35)$ and for the two unpleasant word lists (weapons: $M=2.74$, $S D=0.61$, symptoms: $M=2.57, S D=0.53$ ). Word length ranged from 3 to 9 letters, with longer and shorter words spread equally into prime and target groups. The log frequency of the words, calculated with the WordGen software (Duyck, Desmet, Verbeke, \& Brysbeart, 2004), ranged from 1.24 to 1.87 for the four categories.

Targets and primes were randomly combined into object-object (congruent object target), body-body (congruent body target), object-body (incongruent body target) and body-object (incongruent object target) trials. The 144 priming trials were split into two blocks of 72 trials: a neutral one using the two neutral word lists (kitchen utensils/body parts) and an unpleasant one with the unpleasant word lists (weapons/symptoms). Each block included 18 trials for each congruency $\times$ target combination $(4 \times 18=72$ trials). The order of the blocks was counterbalanced between participants, with a 1-min break in between, during which a shortened version of the music piece used during mood induction was repeated to re-instate mood. The experimental trials were preceded by four practice trials unbeknownst to the participants (with 4 different prime-target pairs), which were not used in the analyses. Response latency and error rate means were computed for each congruency $\times$ target combination.

\section{MEASURES}

Habitual symptom reporting. Participants were screened with the modified Checklist for Symptoms in Daily Life (CSD; Wientjes \& Grossman, 1994), which assesses the frequency of 39 symptoms from different modalities, e.g. low back pain, dyspnea, over the past year on a 5 -point scale $(1=$ never, $5=$ very often). Total scores (range $=39-195)$ were used for participant classification as high $(\geq 100)$ or low symptom reporters $(\leq 75)$, using as cut-offs the upper and lower quartiles of the questionnaire as determined in prior studies (Bogaerts et al., 2008). To confirm participants' classification, the questionnaire was administered a second time after the experiment and only those responding consistently within the determined cut-offs were selected for participation.

Negative affectivity. Trait Negative Affectivity was assessed with the Dutch version (Engelen, De Peuter, Victoir, Van Diest, \& Van den Bergh, 2006) of the Positive and Negative Affect Schedule (PANAS; Watson, Clark, \& Tellegen, 1988). Participants had to indicate to what extent 10 positive and 10 negative adjectives describe how they feel in general $(1=$ very slightly, $5=$ very much). A separate score for Negative Affectivity was calculated and used.

Mood ratings. Affect was assessed before and after mood induction with two pictorial scales, one for valence and one for arousal (Self-Assessment Manikin - SAM, Bradley \& Lang, 1994). Each scale consisted of 9 human figures, presented on screen, showing different levels of valence or arousal, and participants had to select the one depicting their affect at the moment.

Filler questions. To mask the purpose of the mood induction procedure, participants answered filler questions immediately after mood induction regarding the compatibility of the pictures and the music in the emotions they evoke: a) how well the pictures and the music matched overall (on a 0-10 scale), b) which picture best matched the music, and c) which picture was the most emotional. Furthermore, to mask the mood assessment, along with mood ratings, participants answered a question about alertness ("How alert do you feel right now?") which was not included in the analyses.

\section{PROCEDURE}

Participants were seated in a sound-attenuated room with two computers. They were told that they had to perform two different tasks, one emotional and one cognitive, as two different studies were combined in one experimental session, one examining how different people experience combined emotional stimuli and one studying how fast people categorize different kinds of words. After giving written consent and filling in a demographics questionnaire, participants were introduced to the "emotional matching" (mood induction) and the "word categorization" (semantic priming) tasks. A small practice block to illustrate the semantic priming task was also included in this phase.

When participants indicated that they understood what they had to do, the experimenter left the room
Mood and processing styles in high symptom reporters 
and participants started the "emotional matching" task. Prior to mood induction, participants completed the first mood ratings, and at the end the filler questions. They then moved to the other computer, where they first completed mood ratings (serving as post-induction mood assessment) and started the priming task. After the first block of trials (neutral or unpleasant), participants had a 1-minute break, during which an excerpt from the music used for mood induction was repeated via speakers in the room, to re-instate the mood. This break was followed by the second block of priming trials.

After a 5-minute break, participants repeated the procedure for the other mood condition. Mood ratings were again completed before the second mood induction (pre-) and before the second priming task (post-mood assessment). The following day participants completed an on-line assessment that included the CSD, PANAS, as well as valence ratings ( 1 = very unpleasant, 9 = very pleasant) for all the words presented in the priming task, as a manipulation check for the perceived valence of the selected words.

Both tasks were run with the Affect 4.0 software (Spruyt, Clarysse, Vansteenwegen, Baeyens, \& Hermans, 2010), with emotional pictures presented on a 19 inch DELL LCD monitor, while the priming task was run on a 19 inch SONY CRT monitor with a refresh rate of $100 \mathrm{~Hz}$.

\section{DATA ANALYSIS}

Repeated measures ANOVAs with Group (HSR/LSR), Mood (positive/negative) and Time (pre/post) as predictors were conducted with valence and arousal ratings as dependent variables, to check for the successfulness of mood induction. As for the performance on the semantic priming task, due to a priori hypotheses for specificity of effects according to word category, four repeated measures (RM) ANOVAs were conducted for each word category separately (kitchen utensils, body parts, weapons, symptoms) with Group (HSR/LSR) as a between-subject variable and Mood (positive/negative) and Congruency (congruent/incongruent) as within-subject variables. Analyses were first conducted on mean reaction times (RTs). Error rates were too low $(M=3.26, S D=2.36$, range: $0-9.1 \%)$ to be examined separately, so they were combined with RTs into inverse efficiency scores (IES; mean RT of correct responses/proportion of correct responses), which were calculated for each person in each condition and were subjected to the same analyses. Inverse efficiency scores were used to integrate speed and accuracy data to control for differences in speed-accuracy trade-offs between participants (Townsend \& Ashby, 1983). For all analyses, a main effect of Congruency would denote the presence of a priming effect, while a Mood $\times$ Congruency interaction would confirm the expected mood influences on priming. Important for this study is the Mood $\times$ Congruency $\times$ Group interaction, which would denote the hypothesized differential effect of mood on priming in the two habitual symptom reporting groups. All analyses were conducted with SPSS 17.0.

\section{RESULTS}

\section{MANIPULATION CHECKS}

Time (pre/post) $\times$ Mood (positive/negative) $\times$ Group (HSR/LSR) repeated measures ANOVAs were run on valence and arousal ratings collected before and after mood induction (Table 1). The order of mood induction was not entered in the analyses as independent sample $t$-tests did not show significant differences in the ratings due to the order of positive and negative mood. The results indicated that the mood induction procedure modulated perceived valence successfully for both groups, as participants reported more pleasantness after positive compared to negative mood induction, while the two conditions did not differ at the pre-mood baseline assessment (Time $\times$ Mood interaction: $F(1,38)=38.28, p<.001$, partial $\left.\eta^{2}=.50\right)$. As for arousal ratings, these were increased after negative mood induction compared to baseline, but not after positive mood (Time $\times$ Mood interaction: $F(1,38)=5.50, p<.05$, partial $\left.\eta^{2}=.13\right)$. This pattern was, however, observed only for the HSR group, since for LSR both positive and negative mood induction resulted in significant increases in arousal (Time $\times$ Mood $\times$ Group interaction: $F(1,38)=5.50, p<.05$, partial $\left.\eta^{2}=.13\right)$.

Independent sample $t$-tests further showed that the two groups also differed in trait negative affectivity, $t(38)=-5.11, p<.001$, as expected. With regard to the valence of the words used in the priming tasks, analyses showed that the HSR group rated the words in the body parts category, $t(37)=2.38, p<.05$, and the kitchen utensils category, $t(37)=2.76, p<.01$, as more unpleasant than LSR. Nevertheless, these ratings did not correlate significantly with the corresponding priming effects in any of the conditions.

\section{MAIN ANALYSES}

Data reduction. To calculate mean $\mathrm{RT}$ for each condition, trials with no or an incorrect response were removed (3.40\%). Reaction times for correct responses were examined for outliers per person, and RTs exceeding $2.50 S D$ were removed (on average $3.32 \%$ of trials, range $=0-9.38 \%$ ). Means were then calculated per person per condition and checked for outliers across participants using the boxplot function. No participant needed to be excluded. Raw mean RTs 
were log-transformed to correct for normality, but as the results did not differ from those produced using the raw means, the latter are presented here.

$R T s$. Mean RTs (illustrated in Table 2) were entered in four $2 \times 2 \times 2$ RM ANOVAs, one for each word category (see summary of effects in Table 3 ). No significant effects were found for kitchen utensils (neutral objects). For weapons (unpleasant objects), incongruent trials resulted in slower responses than congruent ones (Congruency effect: $F(1,38)=6.68$, $p<.05$, partial $\eta^{2}=.15$ ). However, this effect was only significant during positive and not during negative $\operatorname{mood}($ Mood $\times$ Congruency interaction, $F(1,38)=6.69$, $p<.05$, partial $\eta^{2}=.13$ ). Our test of interest, though, the 3-way Mood $\times$ Congruency $\times$ Group interaction, was not significant for weapons.

With regard to body-related words, no significant effects or interactions were found for body parts (neutral body words). A series of non-significant trends, though, were observed, which are relevant for the study hypotheses. Specifically, incongruent trials tended to overall result in slower responses compared to congruent ones (Congruency effect: $F(1,38)=2.84, p=.10$, partial $\left.\eta^{2}=.07\right)$. This effect was observed in both positive and negative mood for the LSR group, although more profoundly in positive mood, while for the HSR group the congruency effect tended to be observed only in the negative mood, as expected by our main hypothesis (see Figure 1; Mood $\times$ Congruency $\times$ Group interaction: $F(1,38)=2.48$, $p=.12$, partial $\eta^{2}=.06$; Mood $\times$ Congruency for LSR: $F<1$; for HSR: $F(1,17)=2.52, p=.13$, partial $\eta^{2}=.13$ ). As for symptom words (unpleasant body words), incongruent trials resulted in significantly slower responses compared to the congruent ones (Congruency effect: $F(1,38)=4.83, p<.05$, partial
Mood and processing styles in high symptom reporters

Table 1

Means (SDs) of mood ratings before and after each mood induction

\begin{tabular}{lcccc}
\hline \multirow{2}{*}{ Rating } & \multicolumn{2}{c}{ Positive mood } & \multicolumn{2}{c}{ Negative mood } \\
\cline { 2 - 4 } & Pre & Post & Pre & Post \\
\hline Valence (1-9) & $6.43(1.15)^{\mathrm{a}}$ & $6.90(0.93)^{\mathrm{b}}$ & $6.75(1.03)^{\mathrm{a}}$ & $5.43(1.39)^{\mathrm{c}}$ \\
Arousal (1-9) & $3.95(1.48)^{\mathrm{a}}$ & $4.28(1.54)^{\mathrm{a}}$ & $4.13(1.51)^{\mathrm{a}}$ & $5.02(1.58)^{\mathrm{b}}$ \\
\hline
\end{tabular}

Note. Superscript a, b, c: different superscript letters denote significant differences among means at $p<.01$.

Table 2

Mean RTs per group for each word category and each condition of the priming task

\begin{tabular}{|c|c|c|c|c|c|c|}
\hline \multicolumn{3}{|l|}{ Conditions } & \multicolumn{2}{|c|}{ LSR } & \multicolumn{2}{|c|}{ HSR } \\
\hline Word category & Mood & Congruency & $M$ & $S D$ & $M$ & $S D$ \\
\hline \multirow{4}{*}{ Kitchen utensils } & \multirow{2}{*}{ Positive } & Congruent & 551.78 & 94.14 & 532.37 & 92.28 \\
\hline & & Incongruent & 556.48 & 93.39 & 538.70 & 78.08 \\
\hline & \multirow{2}{*}{ Negative } & Congruent & 541.39 & 74.88 & 538.14 & 71.38 \\
\hline & & Incongruent & 544.08 & 69.81 & 537.70 & 69.42 \\
\hline \multirow{4}{*}{ Body parts } & \multirow{2}{*}{ Positive } & Congruent & 523.85 & 86.71 & 520.98 & 72.34 \\
\hline & & Incongruent & 536.53 & 90.50 & 521.20 & 57.82 \\
\hline & \multirow{2}{*}{ Negative } & Congruent & 530.08 & 84.86 & 514.96 & 80.12 \\
\hline & & Incongruent & 534.80 & 67.06 & 531.43 & 58.91 \\
\hline \multirow{4}{*}{ Weapons } & \multirow{2}{*}{ Positive } & Congruent & 542.13 & 83.42 & 536.89 & 86.71 \\
\hline & & Incongruent & 562.86 & 74.13 & 557.94 & 92.65 \\
\hline & \multirow{2}{*}{ Negative } & Congruent & 558.15 & 87.51 & 537.22 & 59.30 \\
\hline & & Incongruent & 555.33 & 72.00 & 548.80 & 60.59 \\
\hline \multirow{4}{*}{ Symptoms } & \multirow{2}{*}{ Positive } & Congruent & 561.52 & 115.92 & 556.45 & 88.69 \\
\hline & & Incongruent & 581.21 & 92.77 & 561.61 & 68.18 \\
\hline & \multirow{2}{*}{ Negative } & Congruent & 571.83 & 96.02 & 546.81 & 68.75 \\
\hline & & Incongruent & 586.20 & 82.99 & 555.97 & 63.18 \\
\hline
\end{tabular}

Note. LSR - low habitual symptom reporters, HSR - high habitual symptom reporters. 
Table 3

Repeated measures ANOVAs for each word category for RTs alone and the combined inverse efficiency scores (IES)

\begin{tabular}{|c|c|c|c|c|}
\hline & $\begin{array}{c}\text { Kitchen tools } \\
\qquad F(d f) \\
\end{array}$ & $\begin{array}{c}\text { Weapons } \\
\qquad F(d f)\end{array}$ & $\begin{array}{c}\text { Body parts } \\
F(d f)\end{array}$ & $\begin{array}{c}\text { Symptoms } \\
F(d f)\end{array}$ \\
\hline \multicolumn{5}{|l|}{ RTs } \\
\hline Group & $0.25(1.38)$ & $0.17(1.38)$ & $0.16(1.38)$ & $0.58(1.38)$ \\
\hline Mood & $0.28(1.38)$ & $0.00(1.38)$ & $0.14(1.38)$ & $0.00(1.38)$ \\
\hline Congruency & $0.61(1.38)$ & $6.68(1.38)^{*}$ & $2.84(1.38)$ & $4.83(1.38)^{*}$ \\
\hline Mood $\times$ Group & $0.42(1.38)$ & $0.37(1.38)$ & $0.00(1.38)$ & $1.50(1.38)$ \\
\hline Congruency $\times$ Group & $0.01(1.38)$ & $0.57(1.38)$ & $0.00(1.38)$ & $0.00(1.38)$ \\
\hline Mood $\times$ Congruency & $0.66(1.38)$ & $6.69(1.38)^{*}$ & $0.29(1.38)$ & $0.01(1.38)$ \\
\hline Mood $\times$ Congruency $\times$ Group & $0.81(1.38)$ & $1.22(1.38)$ & $2.48(1.38)$ & $0.30(1.38)$ \\
\hline \multicolumn{5}{|l|}{ IES } \\
\hline Group & $0.34(1.38)$ & $0.38(1.38)$ & $0.35(1.38)$ & $0.65(1.38)$ \\
\hline Mood & $0.03(1.38)$ & $0.13(1.38)$ & $0.18(1.38)$ & $0.88(1.38)$ \\
\hline Congruency & $0.45(1.38)$ & $4.87(1.38)^{*}$ & $2.94(1.38)$ & $11.87(1.38)^{* *}$ \\
\hline Mood $\times$ Group & $0.61(1.38)$ & $2.21(1.38)$ & $0.05(1.38)$ & $1.47(1.38)$ \\
\hline Congruency $\times$ Group & $0.18(1.38)$ & $0.09(1.38)$ & $0.15(1.38)$ & $0.50(1.38)$ \\
\hline Mood $\times$ Congruency & $2.19(1.38)$ & $6.62(1.38)^{*}$ & $0.67(1.38)$ & $0.20(1.38)$ \\
\hline Mood $\times$ Congruency $\times$ Group & $0.15(1.38)$ & $0.21(1.38)$ & $2.63(1.38)$ & $0.17(1.38)$ \\
\hline
\end{tabular}

$\left.\eta^{2}=.11\right)$, but this was not modulated by mood or group.

Inverse efficiency scores (IES). RM ANOVAs using inverse efficiency scores as dependent measures showed a similar pattern (see Table 3 for a summary). For kitchen utensils, analyses showed a non-significant tendency towards a Congruency effect during positive mood $(p=.16)$, but not during negative mood

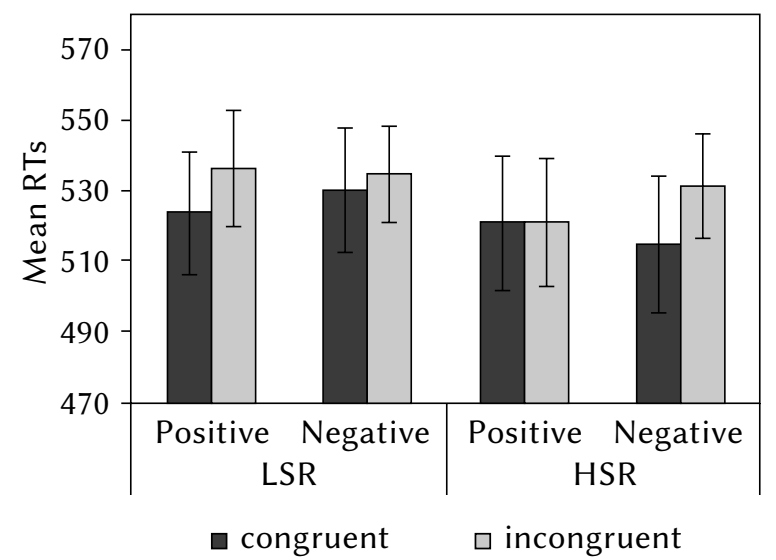

Figure 1. Mood $\times$ Congruency $\times$ Group interaction for the mean RTs of trials with neutral body words (body parts) as targets. LSR - low habitual symptom reporters, HSR - high habitual symptom reporters.
(Mood $\times$ Congruency: $F(1,38)=2.19, p=.15$, partial $\left.\eta^{2}=.06\right)$. As for weapons, a Congruency effect was observed, $F(1,38)=4.87, p<.05$, partial $\eta^{2}=.11$, but again this was significant during positive $(p<.001)$ but not during negative mood (Mood $\times$ Congruency: $F(1,38)=6.62, p<.05$, partial $\left.\eta^{2}=.15\right)$.

For body parts words, a trend towards a Congruency effect was observed, $F(1,38)=2.94, p=.10$, partial

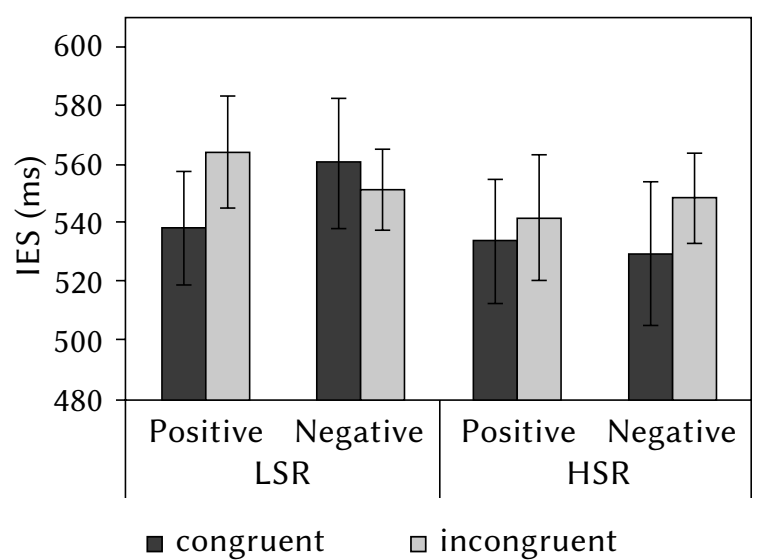

Figure 2. Mood $\times$ Congruency $\times$ Group interaction for the inverse efficiency scores (IES) of trials with neutral body words (body parts) as targets. LSR - low habitual symptom reporters, HSR - high habitual symptom reporters. 
$\eta^{2}=.07$. However, this trend tended to be observed only during positive mood for the LSR group, while for the HSR group it was observed for both positive and negative mood, but most prominently for negative mood (see Figure 2; Mood $\times$ Congruency x Group interaction, $F(1,38)=2.63, p=.11$, partial $\eta^{2}=.07:$ Mood $\times$ Congruency for LSR: $F(1,21)=2.21, p=.15$, partial $\eta^{2}=.10$; Mood $\times$ Congruency for HSR: $F<1$ ). Finally, for symptom words, only a main effect of Congruency was found, $F(1,38)=11.87, p=.001$, partial $\eta^{2}=.24$, which was not modulated by mood or group.

\section{DISCUSSION}

Negative affect has been repeatedly linked to elevated symptom reports, especially in persons experiencing frequent MUS, an effect that has been attributed to increased activations of symptom schemata triggered by unpleasant cues (Bogaerts et al., 2010; Constantinou et al., 2013). This explanation is compatible with findings showing that induced moods alter the way people process incoming information (Clore \& Huntsinger, 2007). Hence, the current study investigated whether induced moods can influence the processing style of body-related information differentially in high symptom reporters. To this end, HSR and LSR individuals completed a semantic priming task, as an indication of their level of schematic processing, after positive and after negative mood induction. To examine the specificity of this effect, the priming task included bodyrelated and body-unrelated words of different valence.

Manipulation checks indicated that our mood induction procedure resulted overall in the expected mood changes. Valence ratings were modulated in accordance with the induced mood for both groups. As for arousal ratings, positive and negative mood induction led to similar increases in arousal for the LSR group, but for HSR positive mood induction did not result in increased arousal. This suggests that positive affect was not induced to the same intensity in the two groups. As emotional arousal has been suggested to influence cognition independently from valence (Van Damme, 2013), the effects of positive mood on priming may differ for the two groups.

With regard to the main analyses, the current findings provide modest support for differential effects of mood on semantic priming in the two groups. As hypothesized, negative mood tended to result in stronger semantic priming effects for the HSR group, but weaker for the LSR group compared to the positive mood condition. This pattern suggests that negative affect may lead to more analytical processing for LSR (which weakens priming effects), but to more schematic processing for HSR (indicated by the stronger priming effects). This pattern, although in the expected direction, failed to reach significance due to various methodological considerations discussed below.
Even though strong effects were absent for the priming task, a series of tendencies is worth pointing out. Firstly, although not in all word categories, mood modulated priming effects as expected. Specifically, it seems that, overall, positive mood tended to result in more pronounced priming effects, i.e. participants' performance was better during congruent than incongruent trials, while under negative mood priming effects tended to be reduced. This pattern confirms prior findings (Hänze \& Hesse, 1993; Storbeck \& Clore, 2008; Topolinski \& Deutsch, 2013), and is in line with predictions stemming from theoretical views such as the affect-as-information theory (Schwarz, 2012). Interestingly, the word category where such effects were not found at all was symptom words, which produced strong priming effects in all conditions. This is quite surprising, as unpleasant words have been previously found to induce less priming compared to positive or neutral ones (Rossell \& Nobre, 2004). It may be, though, that the combination of high self-relevance and unpleasantness exacerbates priming effects for this category in all conditions and for all participants. As symptom words are not typically used in priming experiments, it is unknown which characteristics of this word category may influence priming effects.

As for our main hypothesis, stating that mood influences would be reversed in a high habitual symptom reporting (HSR) group compared to a low one (LSR), this was supported to some extent. A tendency towards such interaction was found only for body part words. Specifically, for HSR negative mood tends to increase priming effects for body parts, i.e. processing of a body word was facilitated when preceded by another body word, suggesting some spreading of activation in a body-related schema. This spread of activation was for HSR more pronounced during negative mood and not during positive mood as the affect-as-information theory would suggest and as was observed for the LSR group. These effects cannot be explained by group differences in perceived valence of the words, or by the group differences in self-reported arousal found for positive mood. As low arousal has been previously linked to increased relational processing (Van Damme, 2013), the difference in arousal cannot explain why HSR, who experienced less arousal, did not show priming effects during positive mood. Furthermore, it cannot explain why priming was intensified during negative mood, as the groups did not differ in their experience of negative mood. Rather, this tendency for augmented priming effects in the negative mood condition possibly points to differences in the way unpleasantness is connected with body-related schemata in memory for high MUS individuals. Thus, these trends are in line with recent conceptualizations of how emotional cues influence symptom reporting, that is via a schema triggering process (Bogaerts et al., 2010; Constantinou et al., 2013), as well as with
Mood and processing styles in high symptom reporters 
current theories that relate MUS to the content and connectivity of symptom representations in memory (Brown, 2004).

\section{LIMITATIONS}

A series of factors may have contributed to the weak findings seen in this study, which should be interpreted as indications for future exploration. Firstly, our sample size was small compared to other similar studies (e.g. Storbeck \& Clore, 2008). Priming effects and reaction time data in general can be noisy and prone to influences of various task parameters (Wentura \& Degner, 2010). Thus, larger samples and/ or a greater amount of trials are typically used in priming tasks, neither of which was feasible in our study, due to sampling and timing restrictions.

Furthermore, our mood induction procedure was shorter compared to other studies (Storbeck \& Clore, $2005,2008)$. This may have led to weaker or more ephemeral induced moods, and consequently to less pronounced effects on the priming task. Mood ratings suggest that this was the case, since although mood was successfully changed in the expected direction, the induced moods were not very extreme. Stronger mood manipulation, with more intense or personally relevant stimuli, could have produced stronger or more long-lasting effects.

Furthermore, a semantic priming task was used in this study as a way to assess participants' level of schematic processing, as the facilitation of target processing seen in congruent trials is considered to reflect a spread of activation to concepts in memory related to the prime (Neely, 1977). However, alternative accounts of the priming effect have also been proposed (de Houwer, Hermans, Rothermund, \& Wentura, 2002). Thus, future research needs to delineate the mechanisms underlying priming effects, for example using advanced statistical methods (Voss, Rothermund, Gast, \& Wentura, 2013). Alternatively, current findings could be replicated with other tasks assessing schematic processing more directly, such as false memory or script recall tasks.

\section{CONCLUSIONS}

The current findings provide some initial indications in support of the hypothesis that affect can have differential influences on people experiencing frequent MUS in daily life. Negative affect seems to result in more schematic processing for these individuals, a finding that could explain the augmenting effect unpleasant cues have on symptom reporting in this group. This further emphasizes the importance of schematic processes in symptom perception, and the affective modulation of these processes. How- ever, further investigation is required to confirm the trends observed in this study.

\section{ACKNOWLEDGEMENTS}

The authors would like to thank Prof. Dr. Eva van den Bussche for her invaluable advice in the preparation of the semantic priming paradigm and Dr. Ilse Van Damme for her input regarding the mood induction stimuli.

The study was funded by Grant OT/10/027 from the University Research Council of University of Leuven.

\section{ENDNOTES}

1 The terms 'affect', 'emotion' and 'mood', although referring to distinct phenomena (Forgas, 1995), are all used here to refer to current affective states, since the current paper brings together findings from different experimental paradigms that utilize either moods or emotions.

2 Explicitly body-related pictures, e.g. disgust pictures, were avoided as they could influence the subsequent priming task.

3 Pleasant: 2208, 2216, 2345, 2398, 2791, 4574, 5260, 7200, 8021, 8030, 8080, 8190, 8200, 8300, 8370, 8461, $8490,8496,8497,8540 ; M_{\text {valence }}=6.90, S D_{\text {valence }}=0.51$, $M_{\text {arousal }}=4.58, S D_{\text {arousal }}=0.49$. Unpleasant: 2455 , 2490, 2691, 2722, 2751, 2753, 4635, 5971, 8485, 9001, 9041, 9046, 9220, 9280, 9331, 9342, 9404, 9440, 9471, $9620 ; M_{\text {valence }}=3.36, S D_{\text {valence }}=0.38, M_{\text {arousal }}=4.69$, $S D_{\text {arousal }}=0.54$.

\section{References}

Albersnagel, F. A. (1988). Velten and musical mood induction procedures: A comparison with accessibility of thought associations. Behaviour Research and Therapy, 26, 79-95.

Anderson, J. R. (1983). A spreading activation theory of memory. Journal of Verbal Learning and Verbal Behavior, 22, 261-295.

Baumgartner, T., Esslen, M., \& Jäncke, L. (2006). From emotion perception to emotion experience: Emotions evoked by pictures and classical music. International Journal of Psychophysiology, 60, 34-43.

Bless, H., Clore, G. L., Schwarz, N., Golisano, V., Rabe, C., \& Wolk, M. (1996). Mood and the use of scripts: Does a happy mood really lead to mindlessness? Journal of Personality and Social Psychology, 71, 665-679.

Bogaerts, K., Janssens, T., De Peuter, S., Van Diest, I., \& Van den Bergh, O. (2010). Negative affective pictures can elicit physical symptoms in high ha- 
bitual symptom reporters. Psychology \& Health, 25, 685-698.

Bogaerts, K., Millen, A., Wan, L., De Peuter, S., Van Diest, I., Vlemincx, E., Fannes, S., \& Van den Bergh, O. (2008). High symptom reporters are less interoceptively accurate in a symptom-related context. Journal of Psychosomatic Research, 65, 417-424.

Bogaerts, K., Notebaert, K., Van Diest, I., Devriese, S., De Peuter, S., \& Van den Bergh, O. (2005). Accuracy of respiratory symptom perception in different affective contexts. Journal of Psychosomatic Research, 58, 537-543.

Bradley, M. M., \& Lang, P. J. (1994). Measuring emotion: The self-assessment manikin and the semantic differential. Journal of Behavioral Therapy and Experimental Psychiatry, 25, 49-59.

Brosschot, J. F. (2002). Cognitive-emotional sensitization and somatic health complaints. Scandinavian Journal of Psychology, 43, 113-121.

Brown, R. J. (2004). Psychological mechanisms of medically unexplained symptoms: An integrative conceptual model. Psychological Bulletin, 130, 793-812.

Brown, H. D., Kosslyn, S. M., Delamater, B., Fama, J., \& Barsky, A. J. (1999). Perceptual and memory biases for health-related information in hypochondriacal individuals. Journal of Psychosomatic Research, 47, 67-78.

Cioffi, D. (1991). Beyond attentional strategies: A cognitive-perceptual model of somatic interpretation. Psychological Bulletin, 109, 25-41.

Clore, G., \& Huntsinger, J. R. (2007). How emotions inform judgment and regulate thought. Trends in Cognitive Sciences, 9, 393-399.

Collins, A. M., \& Loftus, E. F. (1975). A spreading-activation theory of semantic processing. Psychological review, 82, 407-428.

Constantinou, E., Bogaerts, K., Van Diest, I., \& Van den Bergh, O. (2013). Inducing symptoms in high symptom reporters via emotional pictures: the interactive effects of valence and arousal. Journal of Psychosomatic Research, 74, 191-196.

de Houwer, J., Hermans, D., Rothermund, K., \& Wentura, D. (2002). Affective priming of semantic categorisation responses. Cognition \& Emotion, 16, 643-666.

de Wied, M. A., \& Verbaten, M. N. (2001). Affective pictures processing, attention, and pain tolerance. Pain, 90, 163-172.

Duyck, W., Desmet, T., Verbeke, L., \& Brysbaert, M. (2004). WordGen: A tool for word selection and non-word generation in Dutch, German, English, and French. Behaviour Research Methods, Instruments \& Computers, 36, 488-499.

Engelen, U., De Peuter, S., Victoir, A., Van Diest, I., \& Van den Bergh, O. (2006). Verdere validering van de Positive and Negative Affect Schedule (PANAS) en vergelijking van twee Nederland- stalige versies [Further validation of the Positive and Negative Affect Schedule (PANAS) and comparison of two Dutch versions]. Gedrag en $\mathrm{Ge}$ zondheid, 34, 89-102.

Forgas, J. P. (1995). Mood and judgment: the affect infusion model (AIM). Psychological Bulletin, 117, 39-66.

Gasper, K., \& Clore, G. L. (1998). The persistent use of negative affect by anxious individuals to estimate risk. Journal of Personality and Social Psychology, 74, 1350-1363.

Gasper, K., \& Clore, G. L. (2002). Attending to the big picture: Mood and global versus local processing of visual information. Psychological Science, 13, 33-39.

Gohm, C. L., \& Clore, G. L. (2002). Affect as information: An individual differences approach. In: L. Feldmann-Barrett \& P. Salovey (eds.), The Wisdom of Feelings: Psychological Processes in Emotional Intelligence (pp. 89-113). New York: Guilford.

Hänze, M., \& Hesse, F. (1993). Emotional influences on semantic priming. Cognition \& Emotion, 7, 195-205.

Harmon-Jones, E., Gable, P. A., \& Price, T. F. (2013). Does negative affect always narrow and positive affect always broaden the mind? Considering the influence of motivational intensity on cognitive scope. Current Directions in Psychological Science, 22, 301-307.

Henderson, C. J., Hagger, M. S., \& Orbell, S. (2007). Does priming a specific illness schema result in an attentional information-processing bias for specific illnesses? Health Psychology, 26, 165-173.

Hiller, W., Rief, W., \& Brähler, E. (2006). Somatization in the population: from mild bodily misperceptions to disabling symptoms. Social Psychiatry and Psychiatric Epidemiology, 41, 704-712.

Joormann, J., Teachman, B. A., \& Gotlib, I. H. (2009). Sadder and less accurate? False memory for negative material in depression. Journal of Abnormal Psychology, 118, 412-417.

Kroenke, K. (2003). Patients presenting with somatic complaints: epidemiology, psychiatric co-morbidity and management. International Journal of Methods in Psychiatric Research, 12, 34-43.

Lang, P. J., Bradley, M. M., \& Cuthbert, B. (2005). International Affective Picture System (IAPS): Instruction Manual and Affective Ratings. Technical Report A-6. Gainesville, FL: University of Florida.

Lim, S. L., \& Kim, J. H. (2005). Cognitive processing of emotional information in depression, panic, and somatoform disorder. Journal of Abnormal Psychology, 114, 50-61.

Meagher, M. W., Arnau, R. C., \& Rhudy, J. L. (2001). Pain and emotion: effects of affective picture modulation. Psychosomatic Medicine, 63, 79-90.

Meerman, E. E., Verkuil, B., \& Brosschot, J. F. (2011). Decreasing pain tolerance outside of awareness. Journal of Psychosomatic Research, 70, 250-257.
Mood and processing styles in high symptom reporters 
Moss-Morris, R., \& Petrie, K. J. (2003). Experimental evidence for interpretive but not attention biases towards somatic information in patients with chronic fatigue syndrome. British Journal of Health Psychology, 8, 195-208.

Neely, J. H. (1977). Semantic priming and retrieval from lexical memory: Roles of inhibitionless spreading activation and limited-capacity attention. Journal of Experimental Psychology: General, 106, 226-254.

Elena Constantinou, Katleen Bogaerts, Ilse Van Diest,

Omer

Van den Bergh

Pauli, P., \& Alpers, G. W. (2002). Memory bias in patients with hypochondriasis and somatoform pain disorder. Journal of Psychosomatic Research, 52, 45-53.

Rossell, S. L., \& Nobre, A. C. (2004). Semantic priming of different affective categories. Emotion, 4, 354-363.
Schwarz, N. (2012). Feelings-as-information theory. In: P. A. M. Van Lange, A. W. Kruglanski, \& E. T. Higgins (eds.), Handbook of theories of social psychology (pp. 289-308). Thousand Oaks, CA: SAGE.

Skelton, J. A., \& Strohmetz, D. B. (1990). Priming symptom reports with health-related cognitive activity. Personality and Social Psychology Bulletin, 16, 449-464.

Spruyt, A., Clarysse, J., Vansteenwegen, D., Baeyens, F., \& Hermans, D. (2010). Affect 4.0: A free software package for implementing psychological and psychophysiological experiments. Experimental Psychology, 57, 36-45.

Storbeck, J. (2013). Negative affect promotes encoding of and memory for details at the expense of the gist: Affect, encoding, and false memories. Cognition \& Emotion, 27, 800-819.

Storbeck, J., \& Clore, G. L. (2005). With sadness comes accuracy, with happiness, false memory: Mood and the false memory effect. Psychological Science, 16, 785-791.

Storbeck, J., \& Clore, G. L. (2008). The affective regulation of cognitive priming. Emotion, 8, 208-215.

Topolinski, S., \& Deutsch, R. (2013). Phasic affective modulation of semantic priming. Journal of Experimental Psychology: Learning, Memory, and Cognition, 39, 414-436.

Townsend, J. T., \& Ashby, F. G. (1983). The stochastic modeling of elementary psychological processes. Cambridge, England: Cambridge University Press.

Van Damme, I. (2013). Mood and the DRM paradigm: An investigation of the effects of valence and arousal on false memory. The Quarterly Journal of Experimental Psychology, 66, 1060-1081.

Van Diest, I., De Peuter, S., Eertmans, A., Bogaerts, K., Victoir, A., \& Van den Bergh, O. (2005). Negative affectivity and enhanced symptom reports: Differentiating between symptoms in men and women. Social Science \& Medicine, 61, 1835-1845.

Voss, A., Rothermund, K., Gast, A., \& Wentura, D. (2013). Cognitive processes in associative and categorical priming: A diffusion model analysis.
Journal of Experimental Psychology: General, 142, 536-559.

Watson, D., Clark, L. A., \& Tellegen, A. (1988). Development and validation of brief measures of positive and negative affect: The PANAS scales. Journal of Personality and Social Psychology, 54, 1063-1070.

Wentura, D., \& Degner, J. (2010). A practical guide to sequential priming and related tasks. In: B. Gawronski \& B. K. Payne (eds.), Handbook of implicit social cognition: Measurement, theory, and applications (pp. 95-116). New York, NY: Guilford Press.

Wientjes, C. J., \& Grossman, P. (1994). Over-reactivity of the psyche or the soma? Interindividual associations between psychosomatic symptoms, anxiety, heart rate, and end-tidal partial carbon dioxide pressure. Psychosomatic Medicine, 56, 533-540.

Williams, P. G., Wasserman, M. S., \& Lotto, A. J. (2003). Individual differences in self-assessed health: An information-processing investigation of health and illness cognition. Health Psychology, 22, 3-11.

Witthöft, M., Gerlach, A. L., \& Bailer, J. (2006). Selective attention, memory bias, and symptom perception in idiopathic environmental intolerance and somatoform disorders. Journal of Abnormal Psychology, 115, 397-407. 
Appendix

\begin{tabular}{|c|c|c|c|c|c|c|c|}
\hline \multicolumn{8}{|c|}{ Word lists } \\
\hline \multicolumn{2}{|c|}{ Kitchen utensils } & \multicolumn{2}{|c|}{ Body parts } & \multicolumn{2}{|c|}{ Weapons } & \multicolumn{2}{|c|}{ Symptoms } \\
\hline \multicolumn{8}{|c|}{ Primes } \\
\hline Ketel & boiler & heup & hip & granaat & grenade & Diarree & diarrhea \\
\hline Vork & fork & kin & chin & zweep & whip & kramp & cramp \\
\hline schotel & dish & teen & toe & kanon & cannon & Duizelig & dizzy \\
\hline deksel & cover & hals & neck & Bijl & axe & misselijk & sick \\
\hline Pan & saucepan & oor & ear & zwaard & sword & koorts & fever \\
\hline Kom & bowl & schouder & shoulder & bom & bomb & moe & tired \\
\hline \multicolumn{8}{|c|}{ Targets } \\
\hline Lepel & spoon & nek & neck & tank & $\operatorname{tank}$ & infectie & infection \\
\hline Pot & pot & buik & belly & pistool & pistol & benauwd & stuffy \\
\hline schaal & scale & knie & knee & Pijl & arrow & pijn & pain \\
\hline Bord & plate & neus & nose & mes & knife & uitgeput & exhausted \\
\hline Glas & glass & vinger & finger & geweer & rifle & beven & quake \\
\hline Plank & shelf & been & leg & revolver & revolver & stijf & stiff \\
\hline \multicolumn{8}{|c|}{ Practice items } \\
\hline Oven & oven & Voet & foot & Stok & stick & Wonde & wound \\
\hline Bestek & cutlery & Borst & chest & Hamer & hammer & Hoesten & coughing \\
\hline
\end{tabular}

